\title{
Percent Foreign Born
}

National Cancer Institute

\section{Source}

National Cancer Institute. Percent Foreign Born. NCI Thesaurus. Code C53342.

The fraction of a population who's members were born outside of the country. 